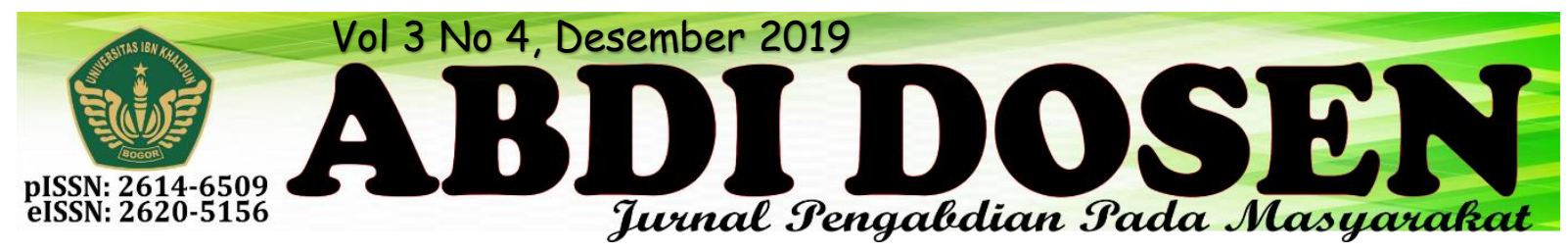

\title{
PERAN MAHASISWA DALAM MENINGKATKAN PENDIDIKAN DI DESA CIBANTENG
}

\author{
Yudiana $^{1}$, Kholidun Ni'am, Fitriya Ariyani Lubis ${ }^{2}$ \\ yudiana@uika-bogor.ac.id \\ Fakultas Ekonomi dan Bisnis Universitas Ibn Khaldun ${ }^{1}$, Mahasiswa KKN Kelompok 14 Tahun $2018^{2}$
}

\begin{abstract}
ABSTRAK
Pendidikan seharusnya sudah menjadi prioritas seluruh masyarakat Indonesia. Tak terkecuali masyarakat desa Cibanteng, Ciampea, Bogor. Anak-anak desa Cibanteng mempunyai semangat dalam belajar. Antusias semangat anak-anak dalam belajar sangat tinggi. Tetapi ada beberapa kendala yang dihadapi. Salah satunya adalah kendala tenaga pengajar. Tenaga pengajar yang ada sangat terbatas. Tenaga pengajar yang ada tidak sesuai dengan jumlah banyaknya anak-anak yang antusias dalam belajar. Kendala yang lainnya adalah sarana prasarana pendidikan. Banyaknya sarana prasarana pendidikan yang rusak. Untuk itu, disini peran mahasiswa sangat dibutuhkan. Mahasiswa membantu sebagai tenaga pengajar salah satunya membantu tenaga pengajar di SDN Cihideung Ilir 05, di PAUD, dan di Majelis. Selain itu, ditambah dengan les bahasa Inggris, menggambar dan mewarnai. Selain membantu dalam tenaga pengajar, disini peran mahasiswa, ikut membantu meningkatkan sarana dan prasarananya. Salah satunya perbaikan majelis. Dengan adanya perbaikan majelis, maka kegiatan belajar mengajar disini lebih aman dan nyaman. Selain perbaikan majelis peningkatan sarana prasarana lainnya adalah penambahan buku baca, dan pemberian AlQur`an. Dengan ini bisa menambah wawasan buat anak-anak dan bisa membentuk akhlakul kharimah.
\end{abstract}

Kata kunci : pendidikan, mahasiswa, masyarakat

\section{PENDAHULUAN}

\section{Latar Belakang}

Kuliah Kerja Nyata merupakan proses pembelajaran bagi mahasiswa S1 Universitas Ibn Khaldun yang dikembangkan melalui kegiatan pengabdian kepada masyarakat dalam berbagai segi kehidupan bermasyarakat. Pelaksanaan KKN ditujukan untuk menumbuh kembangkan empati dan kepedulian civitas akademika UIKA terhadap (1) berbagai permasalahan yang riil dihadapi masyarakat dan (2) pembangunan berkelanjutan yang diperlukan untuk mencerdaskan kehidupan bangsa dan mewujudkan kesejahteraan masyarakat yang sesuai dengan masyarakat islam yang sebenar-benarnya.

Selain itu, kegiatan KKN diharapkan melahirkan pribadi yang tangguh, unggul, berkepribadian mulia, serta dapat menjadi pribadi yang luar biasa ketika sudah terjun dimasyarakat, berjiwa kepemimpinan,. Untuk itu, UIKA mencerdaskan kehidupan bangsa dan mewujudkan kesejahteraan masyarakat yang sesuai dengan masyarakat islam yang sebenar-benarnya. Selain itu, kegiatan KKN diharapkan melahirkan pribadi yang tangguh, unggul, 
berkepribadian mulia, serta dapat menjadi pribadi yang luar biasa ketika sudah terjun dimasyarakat, berjiwa kepemimpinan. Untuk itu, UIKA telah mengembangkan kegiatan $\mathrm{KKN}$, KKN tidak hanya berisi kegiatan kerja civitas akademika UIKA untuk masyarakat tetapi berisi rangkaian kegiatan integratif interdisipliner yang dikemas secara strategis untuk menyelesaian permasalahan secara tuntas dan dilaksanakan bersama masyarkat dengan memerankan masyarakat sebagai pelaku penting dan utama serta melibatkan para pemangku kepentingan lain yang terkait.

Dalam hal ini, mahasiswa diperankan sebagai problem solver, motivator, fasilitator, dan dinamisator dalam proses penyelesaian masalah dan pembangunan/pengembangan masyarakat. Melalui pembaruan konsep tersebut, kehadiran mahasiswa sebagai intelektual muda diharapkan mampu mengembangkan diri sebagai agen atau pemimpin perubahan yang secara cerdas dan tepat menyelesaikan masalah yang dihadapi masyarakatnya.

Pada dasarnya Kuliah Kerja Nyata (KKN) merupakan bentuk pengabdian nyata mahasiswa kepada masyarakat. Setelah mendapatkan materi perkuliahan yang senantiasanya dapat berguna didalam lingkungan masyarakat itu sendiri. Dalam kegiatan pengabdiannya pada masyarakat, mahasiswa memberikan pengalaman ilmu pengetahuan, teknologi, seni, dan agama untuk memberikan pengarahan agar dapat memecahkan masalah dan menanggulanginya secara tepat. Selain itu, pembenahan sarana dan prasarana merupakan kegiatan yang dilakukan serta menjadi program kerja bagi mahasiswa. Dengan kata lain, melalui KKN ini, mahasiswa membantu pembangunan dalam masyarakat/ pemberdayaan masyarakat . Terletak di Kp. Kebon Kopi Desa Cibanteng kecamatan Ciampea Kabupaten Bogor.

\section{Kondisi Wilayah}

Desa Cibanteng adalah salah satu desa di Kecamatan Ciampea yang mempunyai luas wilayah 162.185 Ha. Jumlah penduduk Desa Cibanteng sebanyak 17.570 jiwa yang terdiri dari 8.945 laki-laki dan 8.625 perempuan dengan jumlah kepala keluarga sebanyak 5.515 KK. Sedangakan jumlah keluarga miskin (Gakin) sebanyak 312 KK dengan persentase $15 \%$ dari jumlah keluarga yang ada di Desa Cibanteng.

Batas-batas administratif pemerintahan

Desa Cibanteng Kecamatan Ciampea sebagai berikut:

\begin{tabular}{|c|l|c|}
\hline No & Keterangan & Berbatasan \\
\hline 1 & Utara & Desa Benteng \\
\hline 2 & Selatan & $\begin{array}{c}\text { Desa Cihideung Ilir } \\
\text { dan Desa Cihideung } \\
\text { Udik }\end{array}$ \\
\hline 3 & Barat & $\begin{array}{c}\text { Desa Bojong Jengkol } \\
\text { Dan Desa Benteng }\end{array}$ \\
\hline 4 & Timur & $\begin{array}{c}\text { Desa Babakan } \\
\text { (Kecamatan } \\
\text { Dramaga) }\end{array}$ \\
\hline
\end{tabular}

Dilihat dari topografi dan kontur tanah, Desa Cibanteng Kecamatan Ciampea secara umum berupa tanah dan bangunan yang berada pada ketinggian antara $1000 \mathrm{~m}$ di atas permukaan laut dengan suhu rata-rata berkisar antara 190 s/d 300 celcius. Desa Cibanteng terdiri dari 10 (Sepuluh) RW dan 49 (Empat Puluh Sembilan) RT. Orbitasi dan waktu tempuh dari ibu kota Kecamatan $3 \mathrm{Km}$ dengan waktu tempuh 10 menit dan dari Kabupaten Bogor sekitar $24 \mathrm{Km}$ dengan waktu tempuh 60 menit. 


\section{Mata Pencaharian}

Mata pencaharian penduduk Desa Cibanteng Kecamatan Ciampea Kabupaten Bogor terdiri dari:

- Petani : 46 Orang

- Buruh Tani : 102 Orang

- Pedagang : 254 Orang

- Peternak : 16 Orang

- PNS : 72 Orang

- TNI/POLRI : 51 Orang

- Karyawan Swasta : 358 Orang

- Jasa : 46 Orang

- Wiraswasta : 574 Orang

- Seniman : 15 Orang

- Pengangguran/ Tidak bekerja : 231 Orang

Sarana Pendidikan

Sarana pendidikan umum yang terdapat di Desa Cibanteng Kecamatan Ciampea meliputi:

- Taman Kanak-kanak / PAUD : 7 Buah

- Sekolah Dasar (SD) / MI : 7 Buah

- SLTP / MTS : 1 Buah

- SLTA / MA : 2 Buah

- Pesantren : 3 Buah

- Diniyah : 1 Buah

\section{Sarana Kesehatan}

Sarana kesehatan yang ada di Desa Cibanteng meliputi:

- Puskesmas : - Buah

- Puskesmas Pembantu : 1 Buah

- Balai Pengobatan : 2 Buah

- Dokter 24 Jam : 1 Buah

- Posyandu : 12 Buah

- Pos KB Desa : 12 Buah

\section{METODE}

Metode yang digunakan adalah metode tindakan, yang dimana mahasiswa terjun langsung ke masyarakat untuk mengembangkan ketrampilan-ketrampilan baru atau cara-cara pendekatan baru dan untuk memecahkan masalah dengan cara penerapan langsung dilapangan. Sedangkan tujuan dari metode tindakan itu
- Bidan : 3 Orang

- Rumah Bersalin : 3 Buah

- Tabib : 2 Orang

- Dukun Bayi terlatih : 1 Orang

- Lab Rongen : 1 Buah

Sarana dan Prasarana Ekonomi

- Bank : 3 Buah

- Koperasi Unit Desa : 1 Buah

- Pasar : - Buah

- Industri Rumah Tangga : 6 Buah

- Perusahaan kecil : 25 Buah

- Perusahaan Sedang : 101 Buah

- Perusahaan Besar : 29 Buah

Sarana Ibadah

- Masjid : 12 Buah

- Mushola : 36 Buah

- Gereja : - Buah

- Pura : - Buah

- Vihara : - Buah

- Klenteng : - Buah

Berdasarkan Undang-Undang Nomor 32 Tahun 2004, pemerintahan Desa adalah penyelenggara urusan pemerintah oleh Pemerintah Desa dan BPD dalam mengatur dan mengurus kepentingan masyarakat setempat berdasarkan asal-usul dan adat istiadat setempat yang diakui dan dihormati dalam sistem pemerintahan NKRI. Urusan pemerintahan yang menjadi kewenangan Kabupaten/Kota yang diserahkan pengaturannya kepada Desa adalah urusan pemerintah yang secara langsung dapat meningkatkan pelayanan dan pemberdayaan masyarakat.

sendiri adalah 1. Untuk memperbaiki praktek 2. Untuk pengembangan profesional dalam arti meningkatkan pemahaman atau kemampuan para praktisi terhadap praktek yang dilaksanakannya 3 . Untuk memperbaiki keadaan atau situasi dimana praktek tersebut dilaksanakan. 


\section{REALISASI PROGRAM}

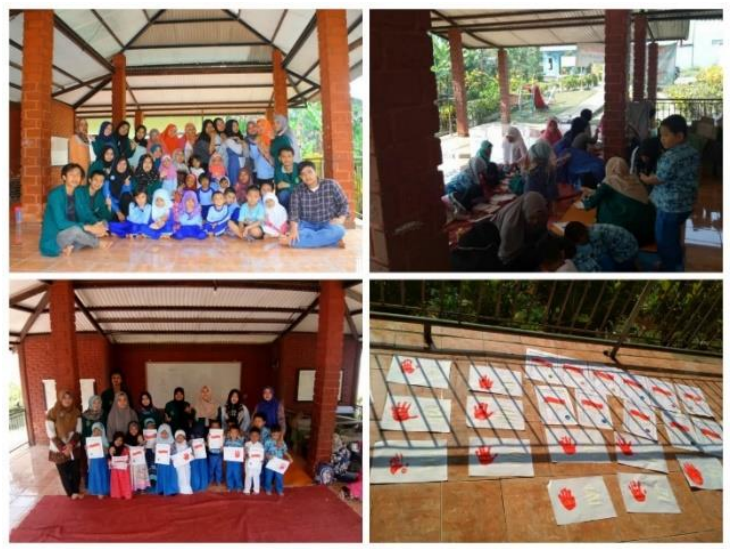

Pengajaran di PAUD

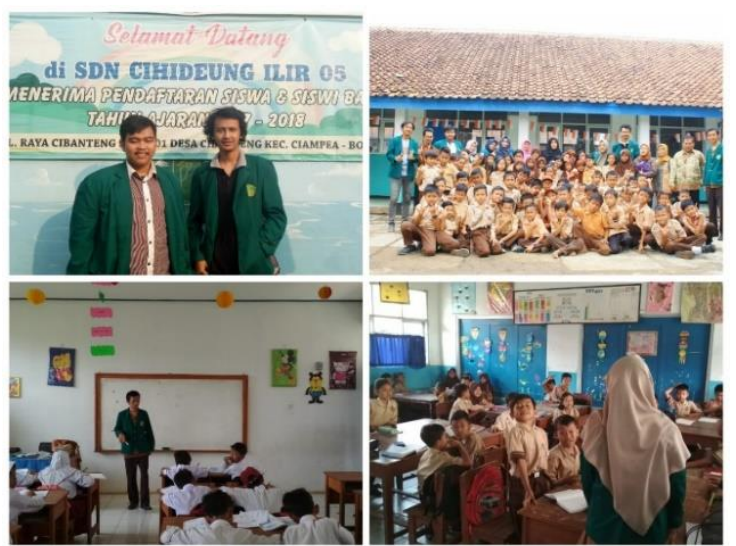

Pengajaran di SDN

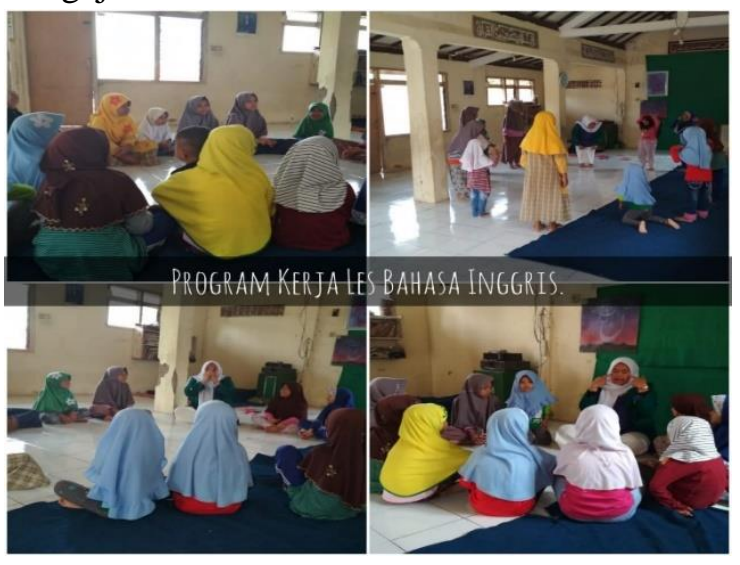

Pembukaan LES Bahasa Inggris
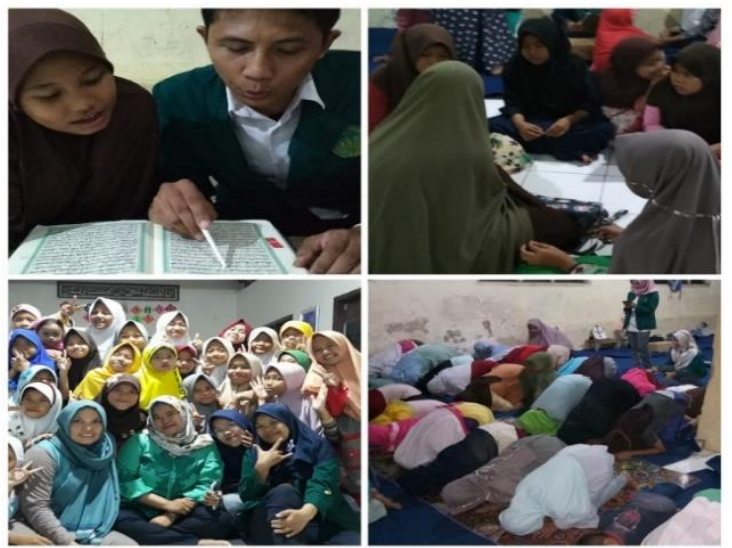

Pengajaran di Majlis Ta'lim

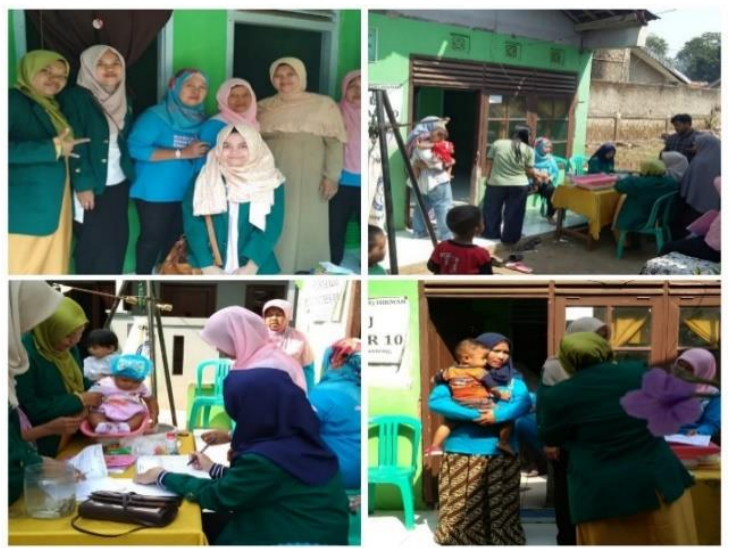

Pos Pelayanan Terpadu

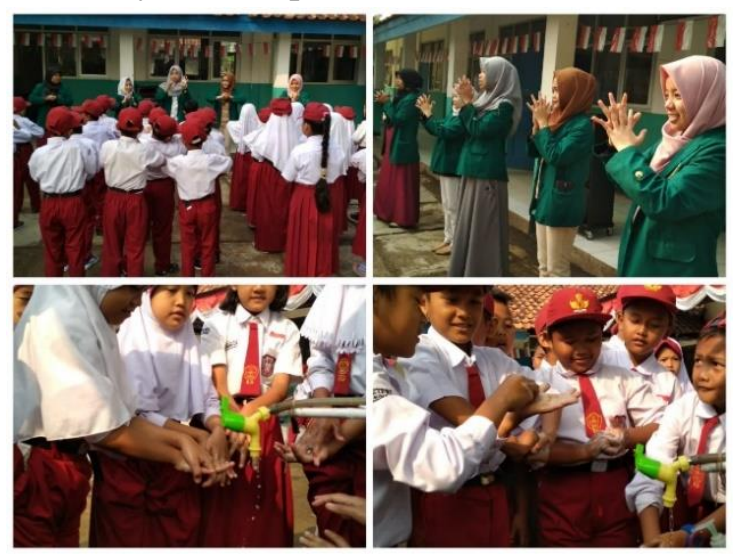

PHBS 


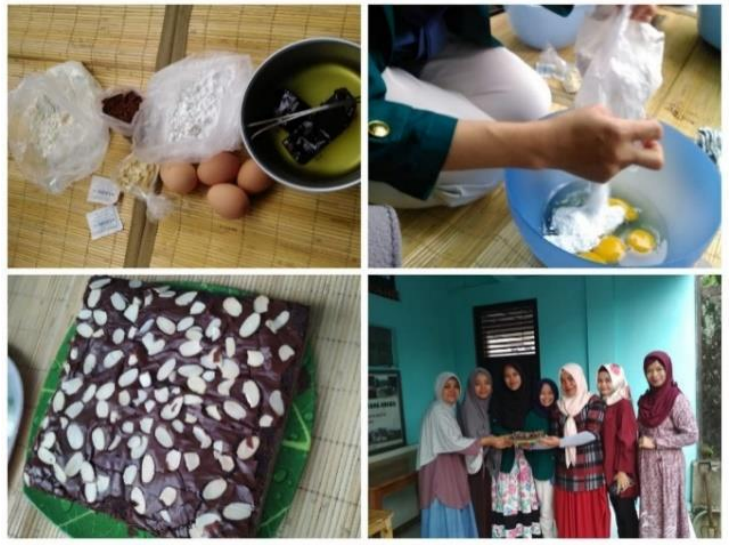

Kegiatan PKK

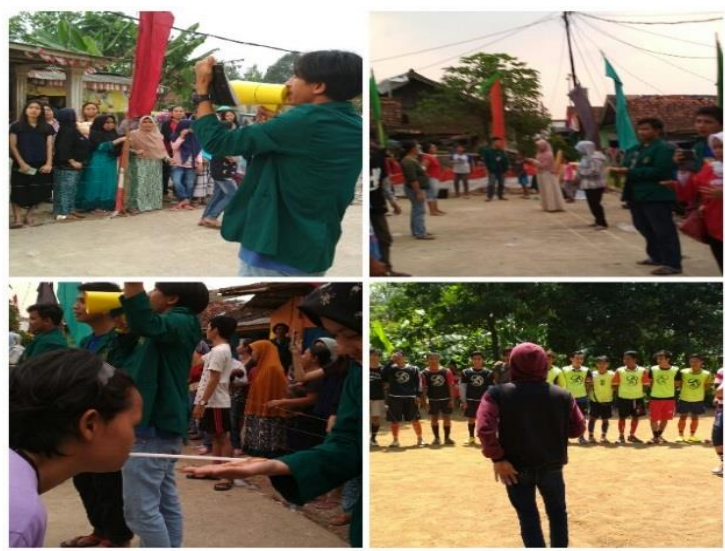

HUT Rakyat Indinesia

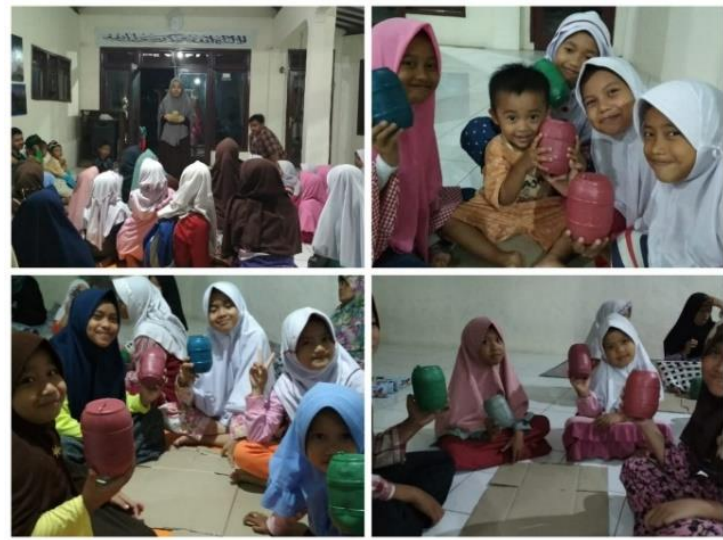

Menabung sejak dini

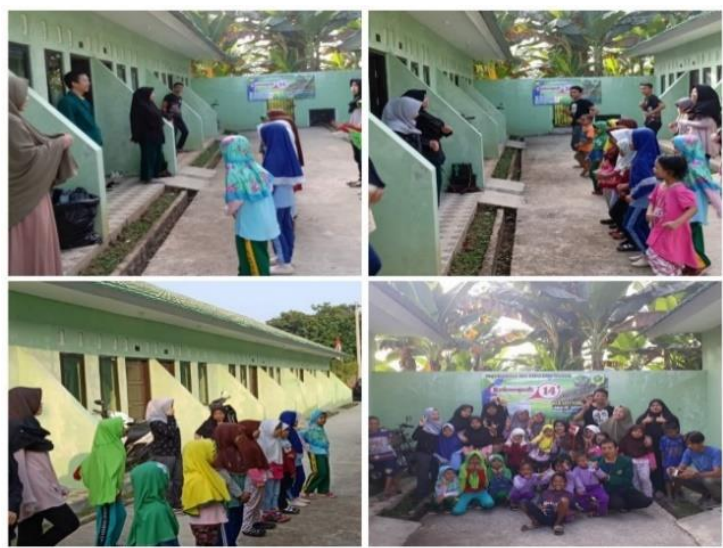

Senam pagi
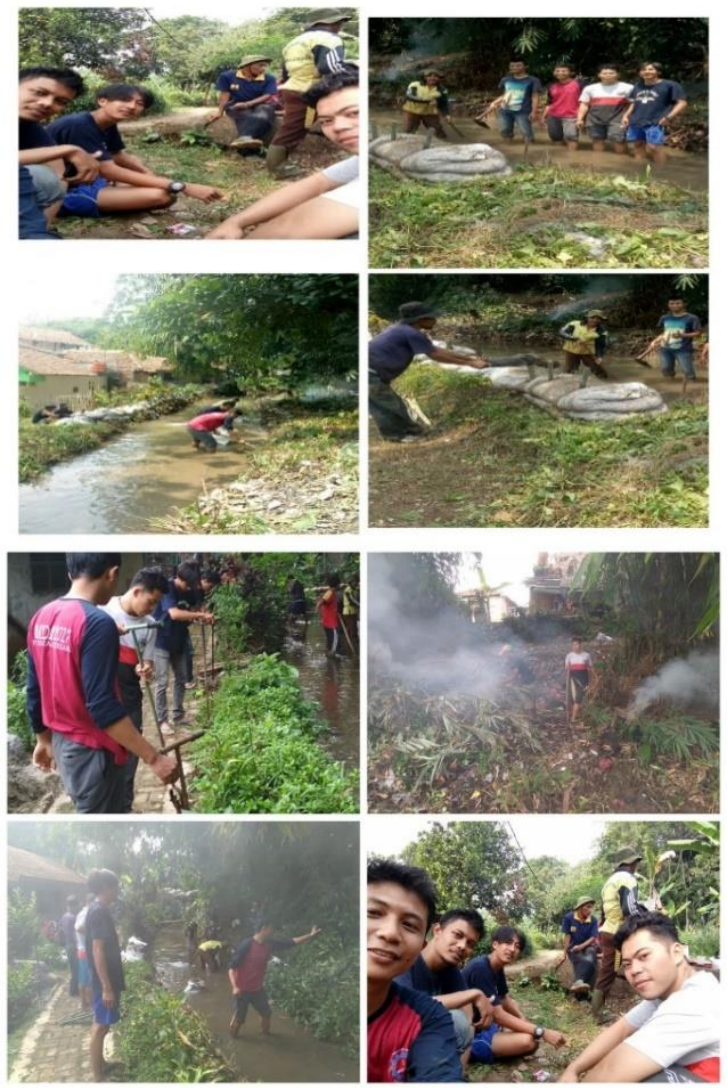

Kerja bakti, pembuatan tanggul dan Biopori

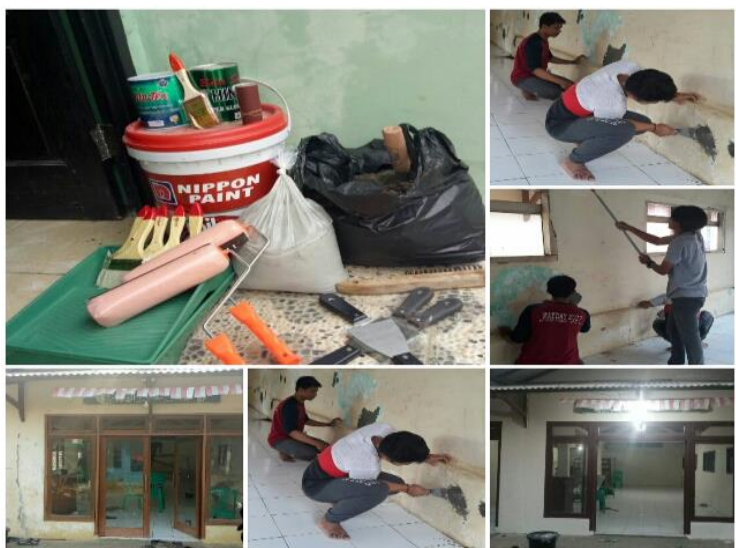

Renovasi Majlis

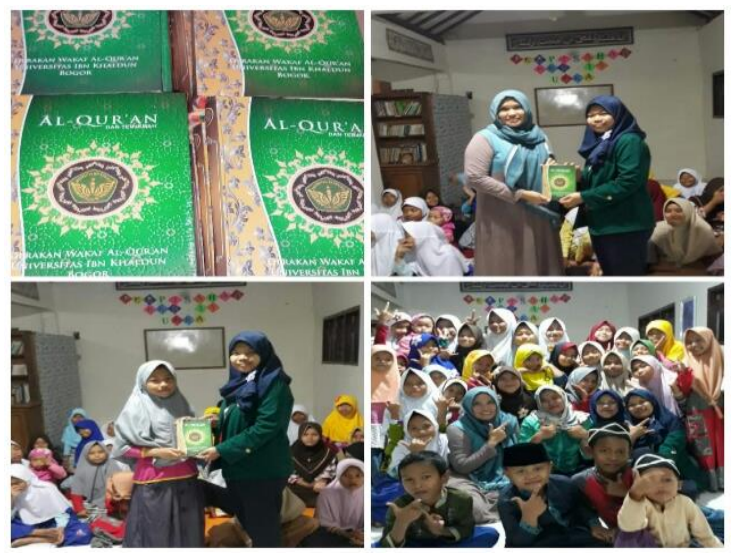

Pembagia Waqaf Al-quran 


\section{KESIMPULAN}

Kesimpulan yang kami dapatkan dalam kegiatan KKN ini adalah Sebagai berikut :

1. Dalam kegiatan KKN Tematik tahun 2018 Universitas Ibn Khaldun Bogor Kel. 14 Kp. Kebun kopi desa Cibanteng Kec. Ciampea. kami mendapat sambutan dan tanggapan dan perhatian yang cukup baik dari warga setempat dan Desa setempat.

2. Kegiatan KKN Tematik ini berlangsung dengan baik dan program-program yang direncanakan dapat terealisasikan dengan optimal tanpa ada kendala.

3. Bekal yang kami berikan kepada masyarakat pada dasarnya, Kami memberikan dukungan dan pengetahuan untuk dapat meningkatkat kesejahteraan. Kami sebagai mahasiswa harus menjadi motivator dan panutan yang baik bagi warga setempat.

4. KKN yang kami lakukan di Kp. Kebon kopi Desa Cibanteng bertujuan membawa kenang-kenangan positif.

5. Kegiatan KKN yang diadakan oleh Universitas Ibn Khaldun Bogor

\section{SARAN}

\section{Untuk Masyarakat Desa}

a. Semua kalangan masyarakat harus lebih meningkatkan lagi kepeduliannya terhadap pendidikan dan kebersihan lingkugan.

b. Semua kalangan masyarakat ikut serta dalam menjaga sarana prasarana pendidikan salah satunya yang ada di majelis

\section{Untuk Perangkat Pemerintahan Desa}

a. Kepala Desa harus terus meningkatkan kinerja dalam menetapkan peraturan desa, memegang kekuasaan pengelolaan keuangan desa,dan membina mempunyai tujuan diantaranya menjalin erat hubungan antara lembaga perguruan tinggi sebagai sumber ilmu pengetahuan dengan masyarakat dan pemerintah setempat semakin baik.

\section{Dampak Bagi Masyarakat}

1) Dengan adanya kegiatan Kuliah Kerja Nyata (KKN) dari mahasiswa Universitas Ibn Khaldun Bogor, maka masyarakat Desa Cibanteng dapat memperoleh berbagai masukan, motivasi, peneguhan dan pandangan bernuansa ilmiah terhadap berbagai macam permasalahan yang dihadapi.

2) Dengan adanya kegiatan Kuliah Kerja Nyata (KKN) mahasiswa Universitas Ibn Khaldun Bogor dapat membantu masyarakat Desa Cibanteng dalam memperlancar pembangunan.

3) Kehadiran mahasiswa Kuliah Kerja Nyata (KKN) mahasiswa Universitas Ibn Khaldun Bogor di Desa Cibanteng perlahan-lahan dapat mengubah pola hidup dan pola pikir masrakat kearah yang lebih praktis dan ekonomis.

perekonomian desa serta terus meningkatkan kemampuan kepemimpinan dan semangat kerja yang tinggi sehingga mampu mensejahterkan masyarakat Desa Cibanteng.

b. Kepala desa beserta jajarannya harus lebih meningkatkan kinerja dalam pembangunan,terutama dalam membangun sarana prasarana pendidikan,agar masyarakat desa Cibanteng memperoleh pendidikan dengan baik.

c. Kepala desa beserta jajarannya lebih meningkatkan lagi terkait dengan 
penglolaan sampah.Meningkatkan sarana prasarana kebersihan lingkungan, seperti penambahan tempat-tempat sampah di pinggiran kali,agar masyarakat tidak membuang

\section{REFERENSI}

enjiner.com,(2017, 07 oktober),Cara Membuat Abstrak Untuk Karya Tulis Ilmiah, Skripsi, Paper Disertai Contoh,Diperoleh 09 September 2018,dari https://enjiner.com/caramembuat-abstrak/

cibanteng ciampea,(2018, 21 maret), Kantor Pemerintahan Desa Cibanteng, Diperoleh 09 September 2018, dari

http://cibantengciampea.blogspot.co $\underline{\mathrm{m} /}$

tips serba serbi, (2014, 01 november), Macam-Macam Penelitian dan Metode Penelitian, Dipeoleh 09 September 2018, dari sampah di kali.Selain itu,masyarakat juga harus diberi pembinaan terkait dengan kebersihan lingkungan,agar masyarakat lebih peduli lagi terhadap kebersihan lingkungan.

https://tipsserbaserbi.blogspot.com/2 014/10/macam-macam-penelitiandan metode.html

kelas indonesia,(2015, 27 juni), Pengertian Kesimpulan, Cara Menentukan,dan Contohnya, Diperoleh 09 September 2018, dari https://www.kelasindonesia.com/201 5/06/pengertian-kesimpulan-cara$\underline{\text { menentukan-dan-contohnya.html }}$

dosen sosiologi, (2018, 14 mei), 8 Contoh Saran dalam Makalah/Karya Ilmiah/Skripsi/Penelitian Lengkap, Diperoleh 09 September 2018, dari http://dosensosiologi.com/contohsaran/ 